\title{
Um novo modelo geológico conceitual do leste do Campo de Inhambu da Bacia do Espirito Santo
}

Igor Andrade Neves*, Cowan

João Batista Françolin, Georisk

Wagner Moreira Lupinacci, UFF

Copyright 2016, SBGf - Sociedade Brasileira de Geofísica

Este texto foi preparado para a apresentação no VII Simpósio Brasileiro de Geofísica, Ouro Preto, 25 a 27 de outubro de 2016. Seu conteúdo foi revisado pelo Comitê Técnico do VII SimBGt, mas não necessariamente representa a opinião da SBGf ou de seus associados. É proibida a reprodução total ou parcial deste material para propósitos comerciais sem prévia autorização da SBGf.

\section{Abstract}

The integrated interpretation of seismic data and wells logs provides information to validate or invalidate a conceptual geological model and aid in reservoirs characterization. The purpose of this research is to show the change in the geological model of the Eastern Inhambu field of the Espirito Santo Basin after drilling the wells. The mapping of four horizons in the seismic sections and the integration of the well logs provided the necessary support for a new proposed geological model and also create the structure maps of the top of basement, top of the Itaunas Formation (top of the Alagoas Age), Campanian unconformity and base of the Tertiary Canyon. We also performed an analysis of seismic attributes to identify new exploration areas.

\section{Introdução}

A Bacia do Espírito Santo é uma bacia sedimentar brasileira localizada ao longo do litoral centro-norte do estado do Espírito Santo e o litoral do extremo sul do estado da Bahia. A evolução tectono-sedimentar desta bacia é representada por três sequências: Rifte (Neocomiano ao Eoaptiano), Transicional (Neo-Aptiano) e Drifte (Albiano ao Recente) (Vieira, 1994). A parte onshore, objeto de estudo desse trabalho, possui uma área de aproximadamente $11.500 \mathrm{Km}^{2}$ e é constituída por 4 províncias geológicas: (I) Plataforma de São Mateus; (II) Plataforma de Regência, (III) Paleocânion de Fazenda Cedro e (IV) Paleocânion de Regência (ver Figura 1).

Atualmente existem 56 campos de produção na Bacia do Espírito Santo. As acumulações de hidrocarbonetos nesta bacia podem ser classificadas de acordo com as idades das rochas reservatórias: (i) arenitos Alagoas localizados principalmente na plataforma de São Mateus e caracterizados por trapas estruturais, (ii) reservatórios calco-arenosos de Idade Albiana localizados na Plataforma de Regência e trapeados estruturalmente e (iii) os reservatórios turbidíticos de Idade CretáceoTerciário localizados dentro dos paleocânions apresentam trapas essencialmente estratigráficas (Wolff et al., 1986). Grande parte dos reservatórios areníticos desta bacia é encontrada em blocos falhados, elevados e/ou basculhados, devido à tectônica rifte atuante em toda área da bacia. Já nos paleocânions predominam as feições de truncamento contra paredes de cânions com trapas estratigráficas.
Os reservatórios dos paleocânions consistem de rochas arenosas com profundidades de 700 a $850 \mathrm{~m}$, porosidades variando entre $23-33,3 \%$, como ocorrem nos Campos de Fazenda Alegre e Fazenda Cedro. As rochas reservatórias são intercaladas por camadas de folhelhos, que podem atingir espessura de até $200 \mathrm{~m}$.

O Campo de Fazenda Alegre está situado no bloco alto do sistema de falhas que compartimenta o paleocânion e é caracterizado por uma série de falhamentos normais, sendo reativados ao longo da deposição da Formação Urucutuca. Tais falhas podem comportar-se como dutos para migração de óleo (Drozinski, 2003). Nos paleocânions, os estratos da Formação Urucutuca podem assentar sobre as Formações Mariricu e até mesmo sobre o embasamento (Viera et al., 1994).

Nos campos de Fazenda Cedro e Fazenda Alegre, que serviram como suportes análogos para os possíveis reservatórios da Formação Urucutuca, os arenitos turbidíticos correspondem aos ambientes de águas profundas depositados durante a fase transgressiva da bacia. De acordo com Standley (1969), os arenitos escoados de um grande cânion submarinho são oriundos de erosão ao longo de estruturas geradas pelos esforços tencionais de rifteamento.

A principal rocha geradora da Bacia do Espírito Santo é formada por folhelhos lacustres da sequencia rifte, denominado Membro Sernambi da Formação Cricaré, que possui um teor de carbono orgânico total (COT) variando de $2 \%$ a $7 \%$. E a migração dos hidrocarbonetos localizados na Formação de São Mateus é de longa distância e esta relacionada com falhamentos e discordâncias que agem como a carries beds regionais.

O principal selo das acumulações da Formação de São Mateus é a anidrita do Membro Itaunas (Formação Mariricu). Já o principal selo do Play Albiano (Plataforma de Regência) das acumulações localizadas nos paleocânions são os folhelhos da Formação Urucutuca.

O entendimento das principais características geológicas das Formações Urucutuca e São Mateus é importante para as discussões e conclusões deste trabalho. A Formação Urucutuca pertence ao Grupo Espírito Santo e faz parte do mesmo sistema deposicional que as Formações Rio Doce e Caravelas (Viera et al. 1994). A Formação Urucutuca é caracterizada na Bacia do Rio Almada por folhelhos com intercalações de conglomerados, calcários e arenitos nas porções mais proximais (Carvalho, 1965).

O Grupo Barra Nova, inicialmente definido como Formação por Asmus et al (1971), compreende as rochas situadas entre os evaporitos do Membro Itaunas e os 
folhelhos da Formação Urucutuca. A Formação São Mateus é caracterizada por espessos pacotes arenosos depositados por leques aluviais e costeiros em paleoambiente marinho (Asmus et al. 1971).

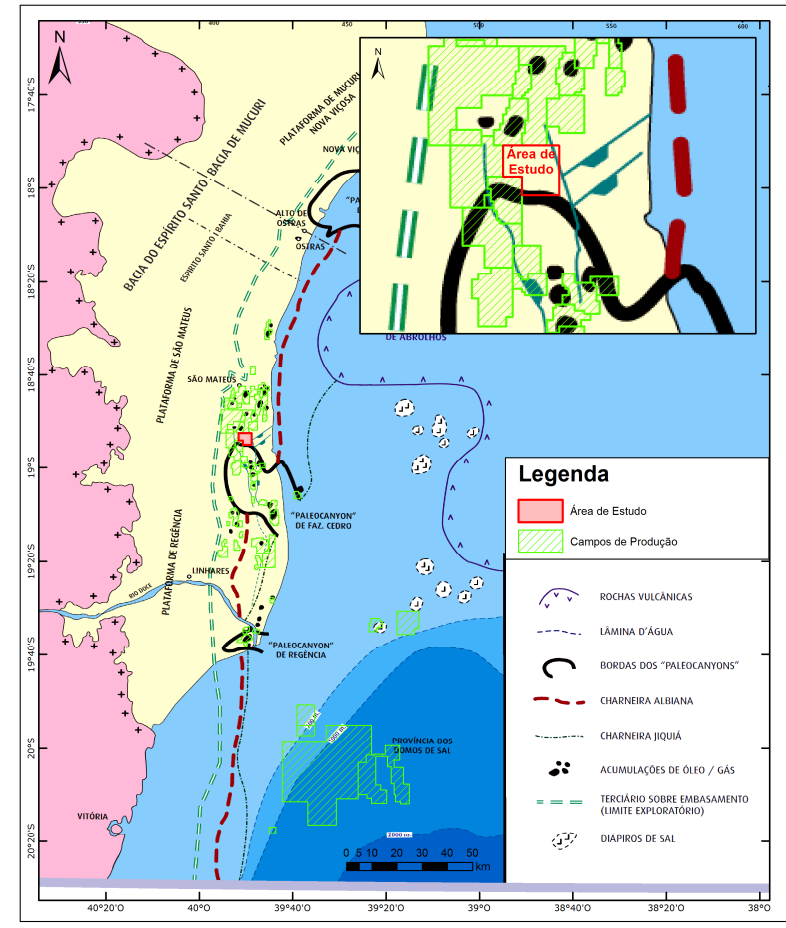

Figura 1: Mapa de Localização da área de estudo mostrando as principais províncias da Bacia do Espirito Santo da parte onshore.

\section{Metodologia}

Por se tratar de um estudo multidisciplinar, o projeto para determinar o novo modelo geológico conceitual e identificar novas áreas exploratórias da região do leste do Campo de Inhambu da Bacia do Espírito Santo envolveu estudos integrados geológico e geofísico.

Abaixo segue uma visão geral e sucinta de como o Projeto foi conduzido e dos métodos de trabalho empregados, a figura 2 mostra de forma simplificada a metodologia presente no trabalho:

1 - Foi realizado um levantamento bibliográfico dos dados e informações.

2 - Recebimento e controle de qualidade dos dados entregues a ANP (dados sísmicos e dados de Poços).

3 - Interpretação dos perfis (litofácies, topos de Formações), utilizando os perfis de Raios Gama, Resistividade, Sônico, Densidade e Neutron.

4 - Controle de Qualidade e dataload de 16 linhas 2D (PSTM) e 1 cubo Sísmico PSTM (0256_N_FAZ_ALEGRE_3D) com $110 \mathrm{Km}^{2}$ para 0 projeto;

5 - Amarração Poço vs. Sísmica;

6 - Interpretação dos topos dos principais horizontes (Embasamento, Mb. latunas, Discordância Campaniana e Canyon Terciário) e de falhas:
7 - Geração de mapas de contorno estruturais dos principais horizontes mapeados;

8 - Análise de atributos sísmicos para a identificação de possíveis áreas exploratórias (Anomalia de amplitude positiva)

9 - Análise dos Poços 1-CW-0001-ES, 1-CW-0002ES,1-CW0003-ES com base nos Perfis de Rios Gama, Resistividade, Sônico, Densidade e Neutron.

10 - Reinterpretação do modelo proposto.

Para o mapeamento sísmico utilizamos os dados do levantamento sísmico denominado Norte de Fazenda Alegre (0256_N_FAZ_ALEGRE_3D).

O processo de interpretação e mapeamento sísmico da área de aproximadamente $100 \mathrm{Km}^{2}$ teve como foco mapear as principais unidades estratigráficas, o que gerou os mapas estruturais do embasamento, do topo do Membro Itaunas (topo do andar Alagoas), discordância Campaniana e Base do Cânion terciário. Estes mapas foram integrados com informações de poços (estratigrafia e litologia) com objetivo de definir o sistema petrolífero e identificar possíveis reservatórios. Dados sísmicos e perfis de poços de outra parte da Bacia do Espírito Santo foram usados para auxiliar no entendimento do arcabouço geológico.

Uma análise de atributos sísmicos também foi realizada e o atributo sísmico amplitude positiva foi utilizado para identificar possíveis reservatórios turbidíticos, devido ao seu potencial de relacionar anomalias de amplitudes com a estratigrafia.

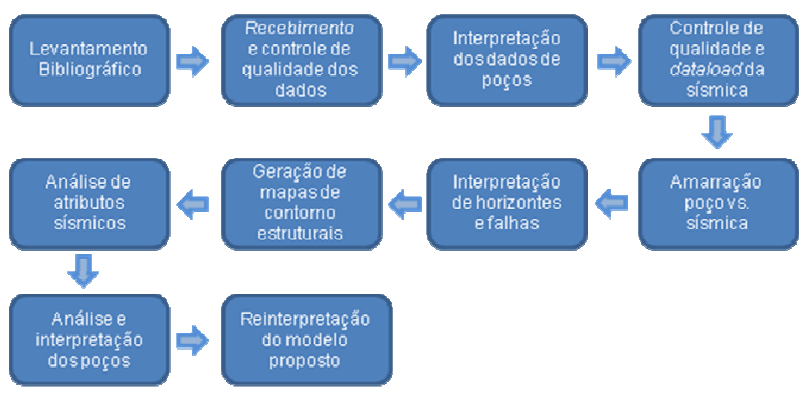

Figura 2: Macroprocesso seguido neste projeto, mostrando de forma simplificada a metodologia utilizada.

\section{Resultados e Discussões}

Os estudos iniciais que foram realizados pelo consórcio Cowan-Labrea identificaram os arenitos turbidíticos da Formação Urucutuca, como as principais rochas reservatórios na área de estudo. As acumulações estariam em trapas estratigráficas de modo análogo ao Campo de Fazenda Cedro. Para esta primeira hipótese, os campos de Fazenda Cedro e Fazenda Alegre serviram como suportes análogos para os possíveis reservatórios da Formação Urucutuca.

O principal reservatório da Plataforma de São Mateus de acordo com a litoestratigrafia formal está localizado no Membro Mucuri da Formação Mariricu e é constituído por arenitos fluvio-deltaíco Neo-Aptianos da fase transicional Já nos paleocânions, os principais reservatórios são 
constituídos pelos arenitos turbidíticos da Formação Urucutuca, de idade Neocretáceo (fase drifte).

Tendo em vista o componente estratigráfico para o trapeamento dos possíveis reservatórios, utilizamos a análise de atributos sísmicos para identificação das possíveis rochas arenosas associadas aos cânions da Fazenda Cedro (Figura 3).

A anomalia positiva que indicaria a presença de arenitos envolvidos por folhelhos dentro de cânions pinch-outs do reservatório principal e contra a discordância sobrejacente não se confirmou após a perfuração dos poços.

Com as perfurações dos poços e a nova interpretação sismoestratigráfica, a Formação Urucutuca, que se acreditava ser o principal reservatório da região, mostrouse muito delgada e em algumas áreas inexistente.

Os perfis dos poços mostraram uma divergência do conceito inicial que indicava um paleocânion preenchido por folhelhos e reservatórios turbidíticos de idade neocretáceo. O modelo geológico previsto não pode ser comprovado, uma vez que a área estudada quase não sofreu influência do paleocânion da Fazenda Cedro.

Os três poços perfurados pela operadora resultaram em indícios de hidrocarbonetos nas Formações São Mateus e Mariricu que são os principais reservatórios da Bacia do Espírito Santo nesta região. Após a perfuração constatou a necessidade de revisão do modelo geológico bem como alteração dos objetivos principais (Turbiditos Cretácicos) e secundários (Arenitos da Fm. Mariricu Mb. Mucuri).

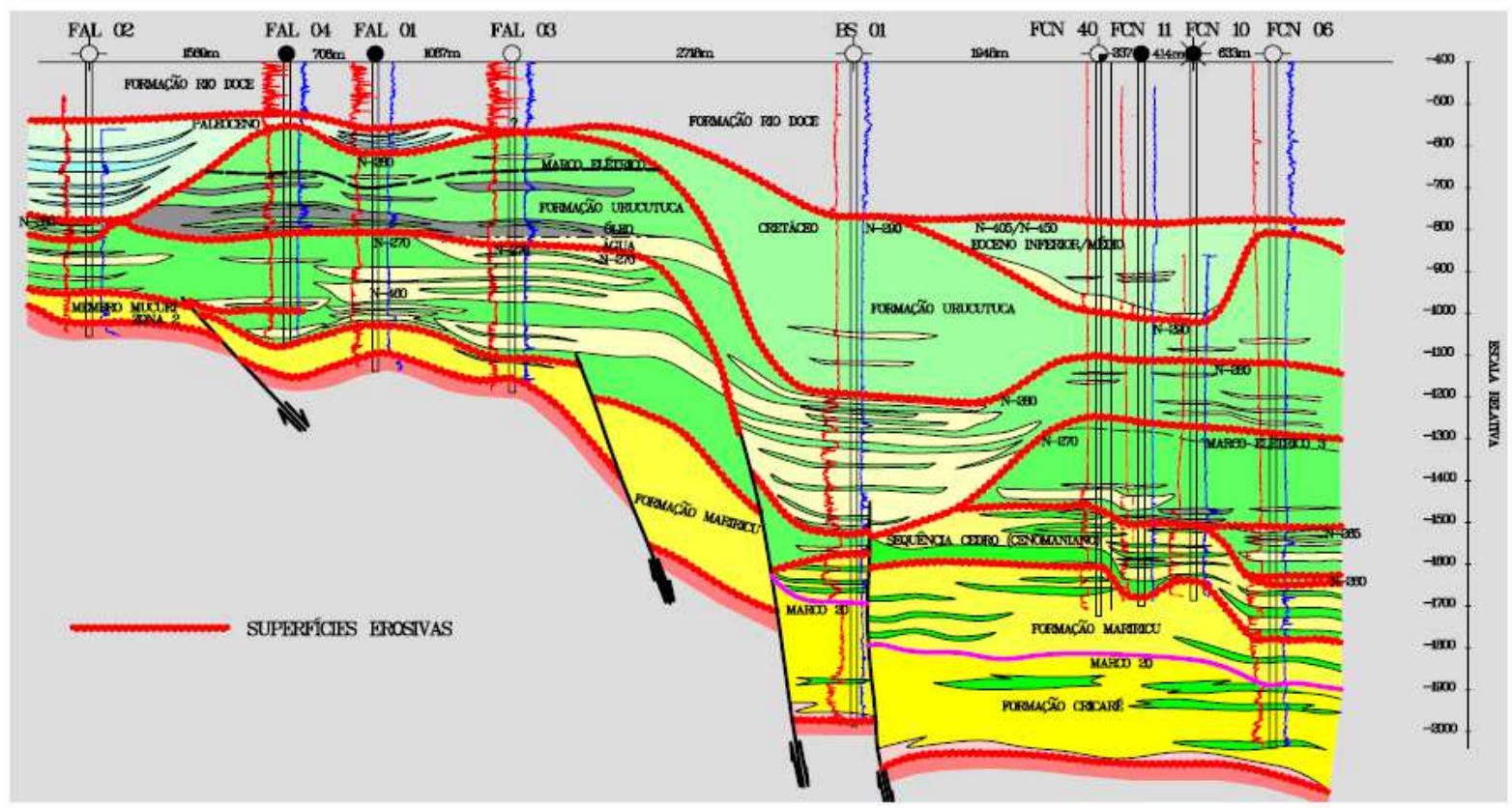

Figura 3: Seção Geológica Regianal (W-E) dos Cânions de Fazenda Cedro e Fazenda Alegre ilustrando as principais estruturais (extraído de Drozinski, 2003).

A interpretação sísmica baseada no conceito de estratigrafia de sequências possibilitou a caracterização temporal e espacial dos seguintes Horizontes: Topo do Embasamento, Topo da Formação Itaunas (Topo do Andar Alagoas), discordância Pre-Urucutuca e da base do Cânion Terciário (Figura 4).

Com a interpretação integrada de dados de perfis e sísmicos, os horizontes cronoestratigráficos foram reinterpretados gerando novos mapas de contorno estrutural que são mais coerentes com a distribuição espacial dos pacotes estratigráficos examinados pelos poços. A figura 5 mostra o modelo inicial e o modelo proposto após a perfuração dos poços.

\section{Conclusão}

A interpretação geológica da parte leste do Campo de Inhambu da Bacia do Espírito Santo usando dados sísmicos, perfis de poços e reservatórios análogos resultou em uma mudança do modelo geológico conceitual. Com os poços perfurados possibilitou afirmar que a área de estudo quase não sofreu influência do paleocânion da Fazenda Cedro. A interpretação integrada contribuiu para delimitar as principais feições estratigráficas e estruturais e também gerou os modelos conceituais de sedimentação e de evolução estrutural. Este estudo mostrou a importância da integração de dados e métodos para corrigir possíveis falhas de construções de modelos geológicos e contribuir para diminuir incertezas exploratórias na perfuração de novos poços. 


\section{Agradecimentos}

Os autores agradecem a Cowan Óleo e Gás por ceder os dados para publicação deste artigo, aos colegas de trabalho que apoiaram a decisão em publicar e a todos que contribuíram direta e indiretamente para a confecção do presente trabalho.

\section{Referências}

Asmus, H. E., Gomes, J. B. \& Pereira, A. C. B., 1971. Integração Geológica Regional da Bacia do Espírito Santo. In: Congresso Brasileiro de Geologia, 25. São Paulo, SBG. Anais v.3, p 235-252.

Carvalho, K. W., 1965. "Geologia da Bacia Sedimentar do Rio Almada". Boletim Técnico da Petrobras, Rio de Janeiro, 8(1), p. 5-55.
Drozinski, V. S., 2003. Caracterização Petrográfica e Geoquímica dos Argilominerais Esmectíticos na

Área do Campo de Fazenda Alegre, Bacia do Espírito Santo.

Stanley, D. J, 1969. Sedimentation in slope and base of slope environments The new concepts of Continental Margin Sedimentation, editor AGI, Washington, p.8-1 a 8-18.

Vieira, R. A. B.; Mendes, M. P., Vieira, P. E., Costa, L. A. R., Tagliari, C. V., Bacelar, L. A. P., Feijó, F. J., 1994. Bacias do Espírito Santo e Mucuri. Boletim de Geociências da Petrobras, Rio de Janeiro, v. 8, n. 1, p. 191-202.

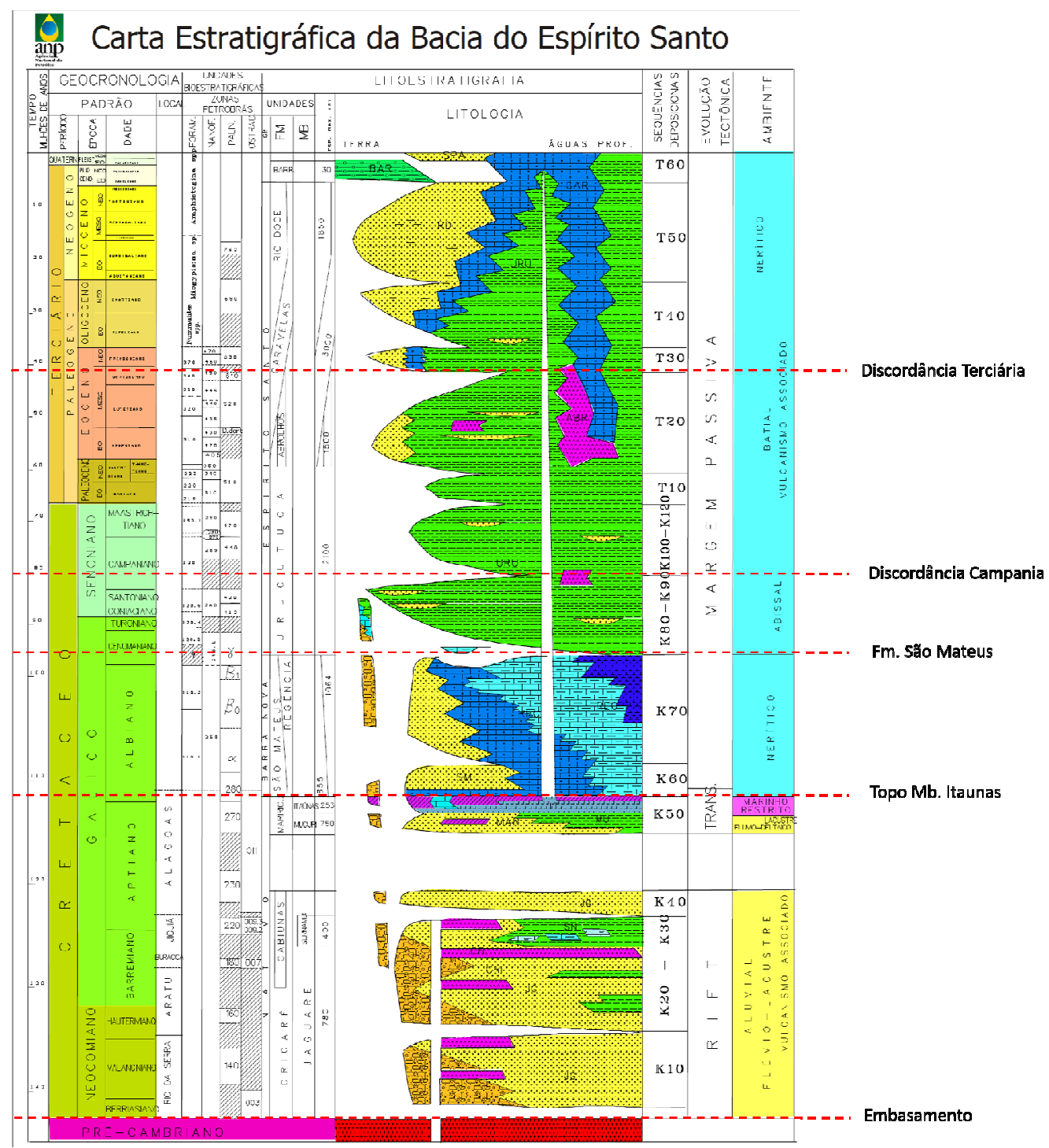

Figura 4 - Carta Estratigráfica da Bacia do Espírito Santo com os principais horizontes mapeados. 


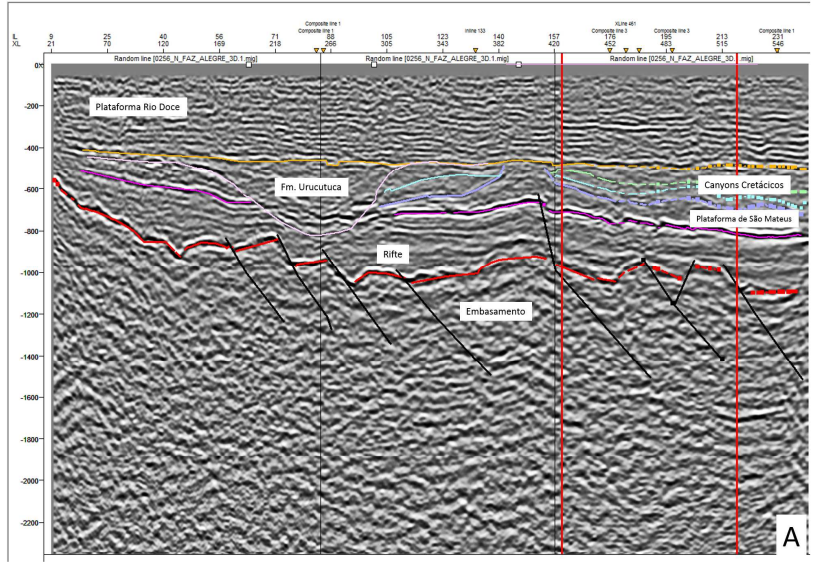

Área de Estudo

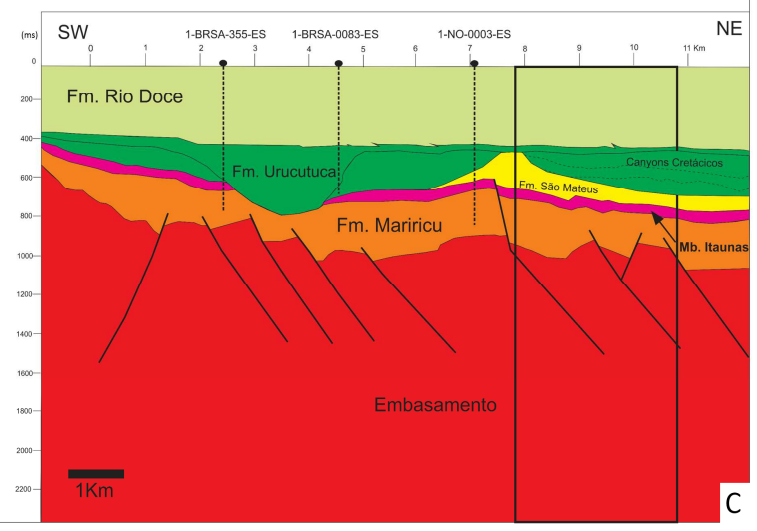

Área de Estudo

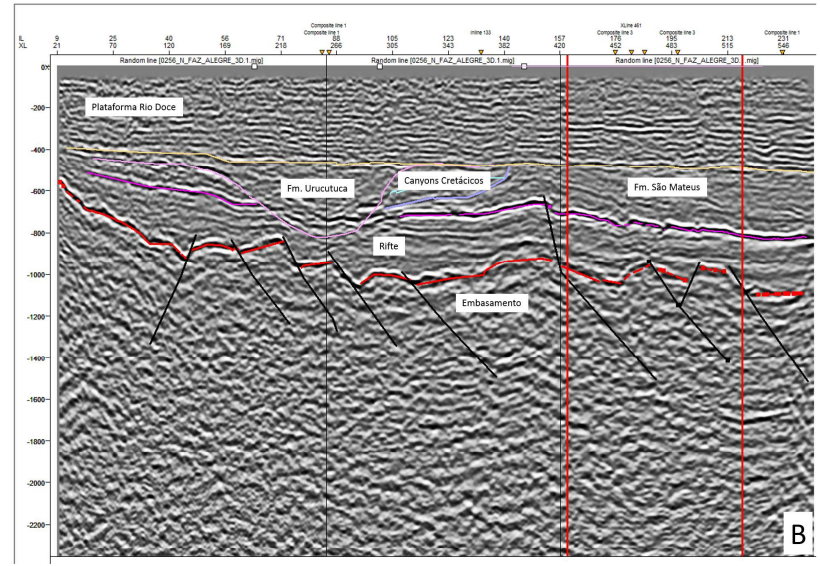

Área de Estudo

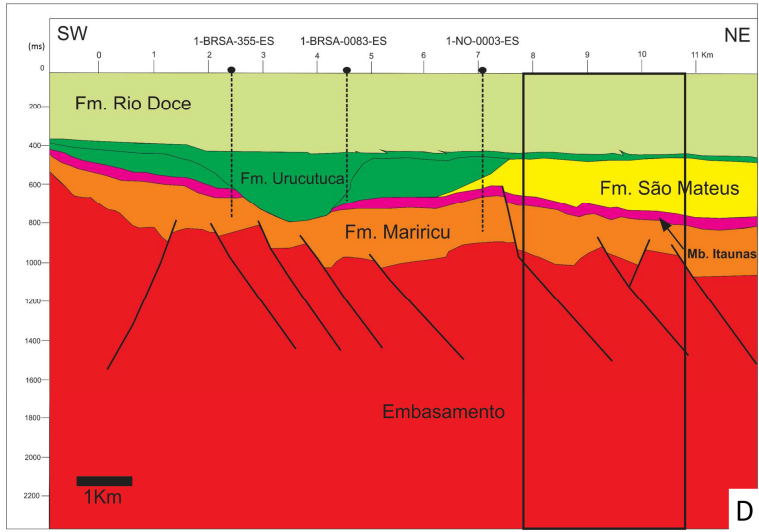

Área de Estudo

Figura 5 - (a) Interpretação sísmica antes da perfuração dos poços; (b) Interpretação sísmica após a perfuração dos poços; (c) Modelo geológico antes da perfuração dos poços; (d) Novo modelo conceitual geológico do leste do Campo de Inhambu. 